\title{
The Emerging Biotherapeutic Agent: Akkermansia
}

\author{
Vipin Chandra Kalia ${ }^{1}$ Chunjie Gong ${ }^{2}$ Ramasamy Shanmugam ${ }^{1}$. \\ Hui Lin ${ }^{3} \cdot$ Liaoyuan Zhang ${ }^{3} \cdot$ Jung-Kul Lee ${ }^{1}$
}

Received: 15 November 2021/ Accepted: 2 December 2021/Published online: 16 December 2021

(C) Association of Microbiologists of India 2021

\begin{abstract}
The human gastrointestinal tract (GIT) is a wellrecognized hub of microbial activities. The microbiota harboring the mucus layer of the GIT act as a defense against noxious substances, and pathogens including Clostridium difficile, Enterococcus faecium, Escherichia coli, Salmonella Typhimurium. Toxins, pathogens, and antibiotics perturb the commensal floral composition within the GIT. Imbalanced gut microbiota leads to dysbiosis, manifested as diseases ranging from obesity, diabetes, and cancer to reduced lifespan. Among the bacteria present in the gut microbiome, the most beneficial are those representing Firmicutes and Bacteroidetes. Recent studies have revealed the emergence of a novel biotherapeutic agent, Akkermansia, which is instrumental in regaining eubiosis and conferring various health benefits.
\end{abstract}

Keywords Akkermansia · Biotherapy · Microbiota ·

Dysbiosis · Eubiosis · Obesity · Diabetes · Cancer · Aging

Vipin Chandra Kalia

vckaliaku@gmail.com

$\triangle$ Liaoyuan Zhang

zliaoyuan@126.com

$\triangle$ Jung-Kul Lee

jkrhee@konkuk.ac.kr

1 Department of Chemical Engineering, Konkuk University, 1 Hwayang-Dong, Gwangjin-Gu, Seoul 05029, Republic of Korea

2 National "111" Center for Cellular Regulation and Molecular Pharmaceutics, Key Laboratory of Fermentation Engineering (Ministry of Education), Hubei University of Technology, Wuhan 430068, People's Republic of China

3 College of Life Sciences, Gutian Edible Fungi Research Institute, Fujian Agriculture and Forestry University, Fuzhou 350002, People's Republic of China

\section{Graphical abstract}

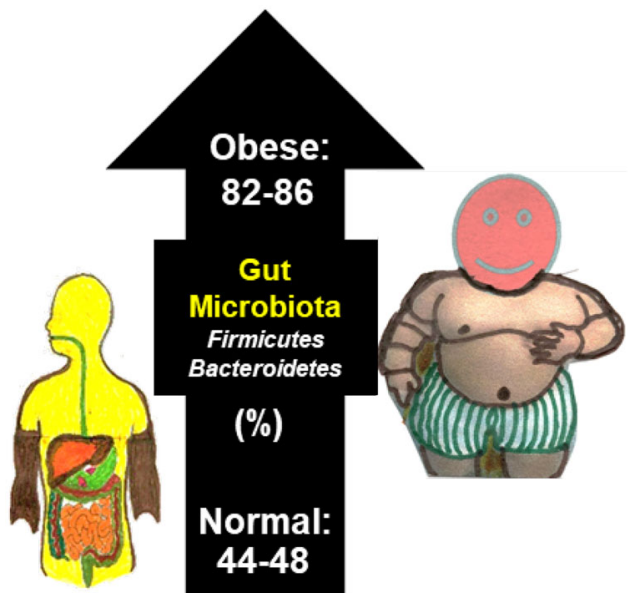

\section{Introduction}

Prokaryotes interact with human beings on their skin surface and within their body [1]. Together these microbial populations constitute the microbiome [2]. The distribution of bacterial populations varies significantly throughout the human body [3, 4]. The estimated bacterial population present in the colon is around two orders of magnitude higher than those present in all other organs. Interestingly, within the gastrointestinal tract (GIT), the stomach and the small intestine harbor a negligible proportion of the total bacterial population, while the colon makes substantial contributions [2]. The diversity of gut microbiota (GM) is manifested by around 1500 different species [5]. This 
ecosystem performs various metabolic activities [6-8]. Among the diverse bacteria which inhabit our gut, the categorization into beneficial and harmful bacteria is not very distinct. Many factors such as age, genotype, diet, nutrition, and environmental components regulate our GM $[9,10]$. A few most prevalent factors which damage our microbiomes are pharmaceutical and personal care products, especially antibiotics and pollutants, including pesticides and insecticides [11, 12]. The dysbiosis of the GM seems to be responsible for various metabolic disorders, such as inflammatory diseases, auto-immune diseases, cancers, mental disorders, ocular diseases, and diabetes $[13,14]$. Comparing microbiomes from healthy individuals with those manifesting metabolic disorders or diseased conditions established their role in regaining eubiosis and maintaining health [15-20]. The major problem is to establish a correlation between bacterial population dynamics and disease conditions. This paper aims to identify bacteria that are critical for maintaining health and how to enrich them in the GIT. The future prospects are the development of strategies for overcoming dysbiosis and regaining health.

This article provides insights into the role of GM in maintaining health based on the studies on germ-free animal models. These works provided the necessary information that the mucus layer in the GIT and its associated microbiota is critical for preventing the proliferation of pathogens and promoting the growth and metabolism of the probiotic bacteria. Comparative genomics revealed the changes in various bacterial population densities in the GM and multiple diseases such as obesity, diabetes, cancer, and aging. Further, prebiotics, which promote the abundance of Akkermansia, is critical in preventing diseased conditions.

\section{The Hub of Microbiota}

Human GIT is the hub of microbial activities. GIT has a mucous lining that produces mucus, which is composed of glucoproteins called mucins. The mucus layer and microbiota harboring it act as a defense system against noxious substances, cytokines, and pathogens. Toxins and pathogens inhibit mucin production, which leads to diverse pathological conditions, especially chronic inflammatory diseases. It is thus imperative to identify the factors, which modulate the mucus barrier and accordingly develop innovative strategies to circumvent these disorders [21]. The consumption of antibiotics perturbs the commensal floral composition within the GIT. This interaction supports the epithelial colonization with the enteric pathogen (Salmonella Typhimurium and Clostridium) [22]. Germfree mice models furnished further information regarding the effects of microbiotal composition and mucus layer.
The addition of probiotics induces the expression of mucins-MUC2 and MUC3, which prevent the adherence of Enteropathogenic Escherichia coli (EPEC) to the epithelial lining [23]. Recent works have highlighted the role of Akkermansia muciniphila in various health benefits $[24,25]$. A. muciniphila, a gram-negative bacteria, was isolated from human feces [26], and it accounts for up to $4 \%$ of the total bacterial population in the large intestine [27] (Fig. 1). This article elucidates the role of A. mисiniphila in improving health by regulating various metabolic disorders.

\section{Microbiome and Human Health}

\section{Diet}

Diet is a principal constituent, which significantly impacts our GM composition (Fig. 2). A high-fat, low-fiber diet, largely burgers, potato chips, cake, ice cream, and cheese fed to African-Americans for two weeks, increased the colon's inflammation. It also resulted in lower butyrate production, which is otherwise essential for reducing colon cancer. Rural Africans eating low-fat, high-fiber content did not show any ill effects. It implied that low-fiber processed foods result in lower availability of feed for gut bacteria. In the long run, the population density of commensal bacteria reduced drastically, and their contribution became insignificant. The absence of these bacteria provides an opportunity for the other group of non-short-chain fatty acids (SCFA) producers to feed on the mucus layer, making the gut lining susceptible to invasion by pathogenic bacteria [28]. The information generated from mice fed on a high-fat diet further supports the beneficial aspects of $A$. muciniphila. (Fig. 3). Here, a negative correlation between the abundance of this specific bacterium and inflammation and metabolic syndromes such as fatty acid oxidation and browning of white adipocytes was recorded [29]. GM also regulates the host metabolic activities essential for obtaining vitamin $\mathrm{K}$, folate, and SCFAs. GM is instrumental in the metabolism of non-digestible carbohydrates into SCFAs, which increase mucus production and its secretion. Here, butyrate plays a critical role in inhibiting inflammation and tumor growth. Low concentrations of SCFAs induce the expression of MUC2, which can be reversed by increasing the availability of the same [21]. Dietary SCFAs contribute towards conferring mucosal immunity and preventing inflammation [30]. These nutrients help the immune system prevent the proliferation of the pathogenic microbe [31, 32]. 
Fig. 1 Role of Akkermansia in preventing proliferation of bacterial pathogens in human gut

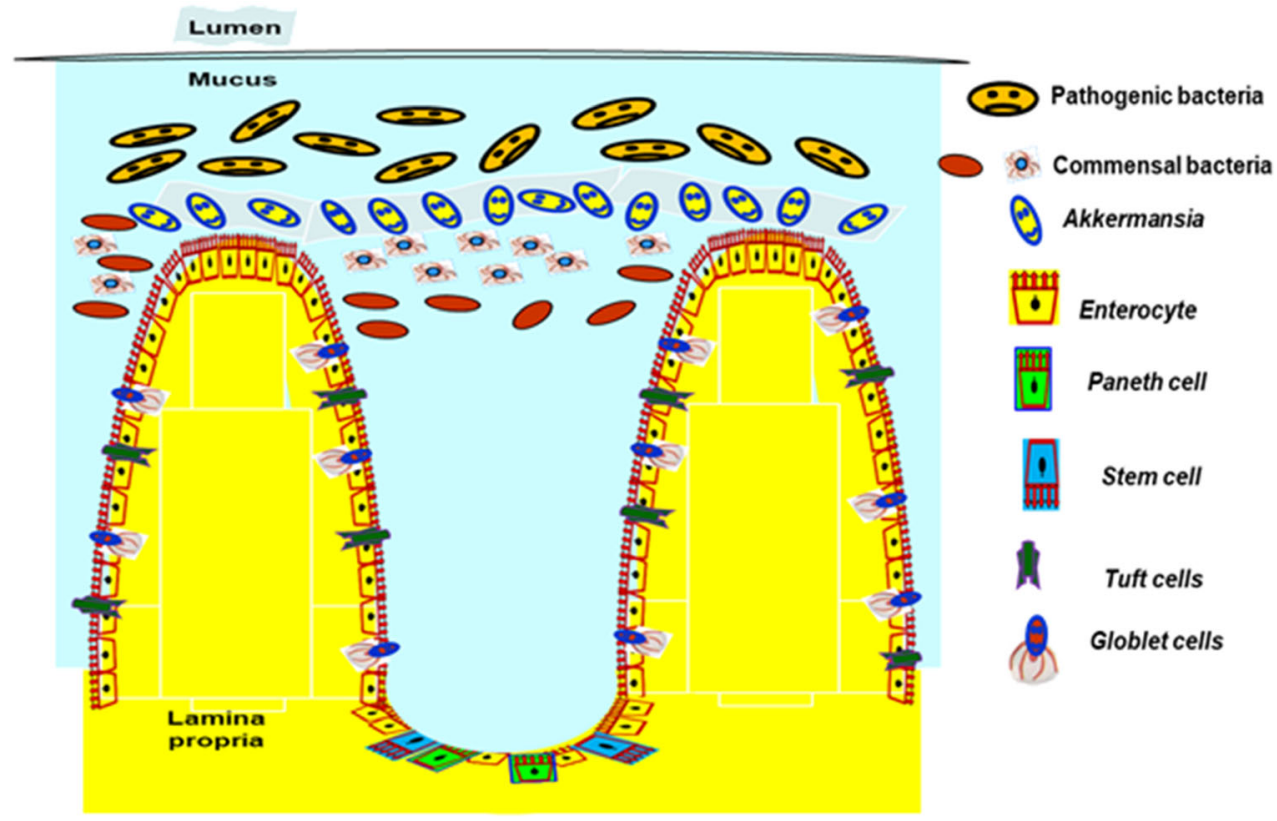

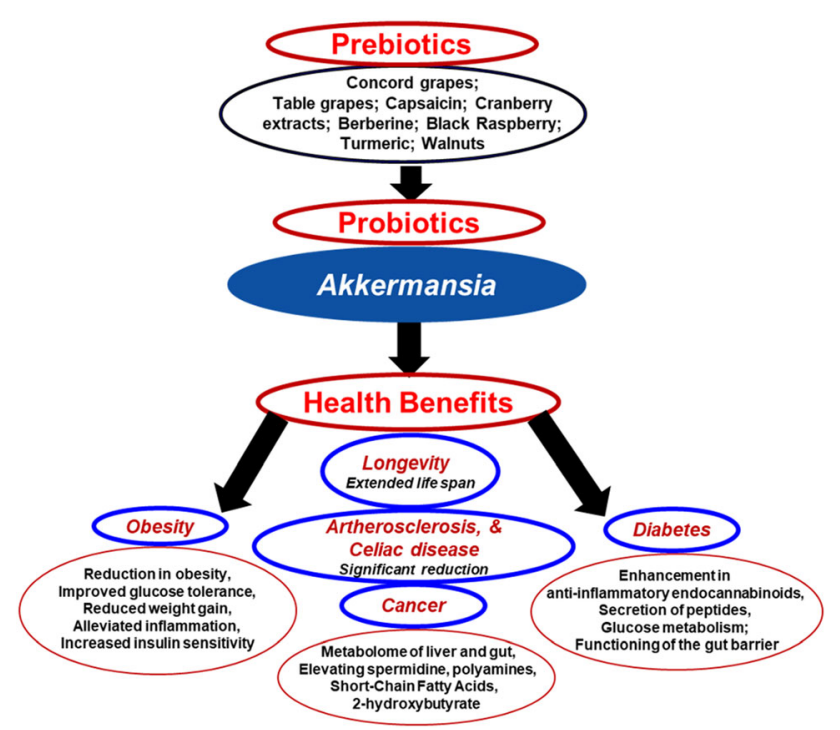

Fig. 2 Benefical effects of Akkermansia to human beings

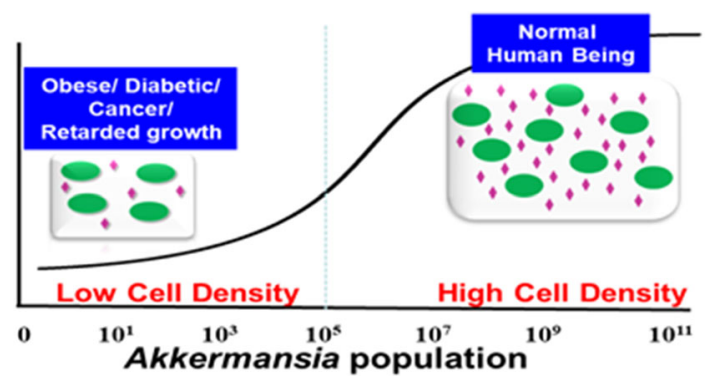

Fig. 3 Abundnace of Akkermansia in human gut microbiota prevents diseases

\section{Obesity}

Mice (C57BL/6J) fed with a high-fat diet supplemented with $3-5 \%$ table grapes significantly altered the gut microbial population. At $3 \%$ grape supplementation, the significant changes were in reducing Bilophila wadsworhia (a dissimilatory sulpfite reducer) and a Desulfobacter spp. (sulidogenic bacteria). The most important part of the dietary treatment was increasing A. muciniphila population, which reduced obesity (Table 1) [33]. A similar effect on supplementing a high-fat diet with capsaicin to mice improved its glucose tolerance and reduced weight gain. These changes were linked to an abundance of A. muciniphila bacterial population and a decrease in genera representing Proteobacteria [34]. Direct response to oral supplementation of A. muciniphila alleviated the inflammation (reduced hyperlipidemia) and endoplasmic reticulum stress [35]. A few other studies have shown a shift towards the abundance of $A$. muciniphila accompanied by a decline in Bacteroidetes and Firmicutes, B. wadsworthia, Desulfobacter spp. in C57BL/6J mice models fed with polyphenol-rich feed such as concord grapes, cranberry extracts, and table grapes, berberine and walnuts (Fig. 2). Among the various health benefits recorded in the animals were: reduced weight gain, reduced adiposity, reduced visceral fat, suppression of inflammation and oxidative stress, increased insulin sensitivity (Table 1) [36-40]. A diet rich in black raspberry resulted in the abundance of $A$. muciniphila in the GM of C57BL/6J mice. It regulated the metabolic pathways related to vitamin synthesis, oxidative stress, and those responsible for amino acid and carbohydrate biosynthesis [41]. 
Table 1 Diversity of therapeutic potentials of Akkermansia

\begin{tabular}{|c|c|c|c|c|c|}
\hline $\begin{array}{l}\text { Metabolic } \\
\text { disorder }\end{array}$ & Host & Treatment & Metabolic changes & Impact in gut microbiota & References \\
\hline Obesity & $\begin{array}{l}\text { Mice } \\
\quad(\mathrm{C} 57 \mathrm{BL} / 6 \mathrm{~J})\end{array}$ & $\begin{array}{l}\text { High-fat diet with } \\
\text { 3-5\% } \\
\text { Table grapes }\end{array}$ & $\begin{array}{l}\text { Akkermansia muciniphila } \\
\text { induced reduction in } \\
\text { obesity }\end{array}$ & $\begin{array}{l}\text { Abundance of A. muciniphila; Reduction in } \\
\text { Bilophila wadsworthia and Desulfobacter } \\
\text { spp. }\end{array}$ & {$[33]$} \\
\hline Obesity & Mice & $\begin{array}{l}\text { High-fat diet with } \\
\text { capsaicin }\end{array}$ & $\begin{array}{l}\text { Improved glucose } \\
\text { tolerance and reduced } \\
\text { weight gain }\end{array}$ & $\begin{array}{l}\text { Abundance of } A . \text { muciniphila; decrease in } \\
\text { genera representing Proteobacteria }\end{array}$ & {$[34]$} \\
\hline Obesity & Mice & $\begin{array}{l}\text { Chow diet-fed and } \\
\text { oral } \\
\text { supplementation } \\
\text { of } A \text {. muciniphila }\end{array}$ & $\begin{array}{l}\text { Alleviated the } \\
\text { inflammation (reduced } \\
\text { hyperlipidemia) and } \\
\text { endoplasmic reticulum } \\
\text { stress }\end{array}$ & Abundance of A. muciniphila & {$[35]$} \\
\hline Obesity & $\begin{array}{l}\text { Mice } \\
\quad(\mathrm{C} 57 \mathrm{BL} / 6 \mathrm{~J})\end{array}$ & $\begin{array}{l}\text { Polyphenol-rich } \\
\text { feed such as } \\
\text { concord grapes, } \\
\text { cranberry } \\
\text { extracts, and } \\
\text { table grapes, } \\
\text { berberine and } \\
\text { walnuts. }\end{array}$ & $\begin{array}{l}\text { Reduced weight gain, } \\
\text { reduced adiposity, } \\
\text { reduced visceral fat, } \\
\text { suppression of } \\
\text { inflammation and } \\
\text { oxidative stress, } \\
\text { increased insulin } \\
\text { sensitivity }\end{array}$ & $\begin{array}{l}\text { Abundance of A. muciniphila accompanied by } \\
\text { a decrease in Firmicutes and Bacteroidetes, } \\
\text { Bilophila wadsworthia, Desulfobacter spp }\end{array}$ & {$[36-40]$} \\
\hline Obesity & $\begin{array}{l}\text { Mice } \\
\quad(\mathrm{C} 57 \mathrm{BL} / 6 \mathrm{~J})\end{array}$ & $\begin{array}{l}\text { Diet rich in black } \\
\text { raspberry }\end{array}$ & $\begin{array}{l}\text { Metabolic pathways } \\
\text { related to vitamin } \\
\text { synthesis, oxidative } \\
\text { stress, and carbohydrate } \\
\text { and amino acid } \\
\text { biosynthesis }\end{array}$ & Abundance of A. muciniphila & {$[41]$} \\
\hline Diabetes & $\begin{array}{l}\text { Type } 2 \\
\text { diabetic } \\
\text { (T2DM) } \\
\text { mice }\end{array}$ & $\begin{array}{l}\text { Administration of } \\
\text { A. muciniphila }\end{array}$ & $\begin{array}{l}\text { Enhanced the } \\
\text { concentration of anti- } \\
\text { inflammatory } \\
\text { endocannabinoids, } \\
\text { secretion of peptides }\end{array}$ & Abundance of A. muciniphila & {$[42]$} \\
\hline Diabetes & $\begin{array}{l}\text { Human } \\
\text { Colombian } \\
\text { T2DMs }\end{array}$ & $\begin{array}{l}\text { Undergoing drug } \\
\text { treatment - } \\
\text { metformin }\end{array}$ & - & $\begin{array}{l}\text { Higher population density A. muciniphila and } \\
\text { SCFA-producing bacteria: Butyrivibri, } \\
\text { Bifidobacteria, and Megasphaera, }\end{array}$ & {$[43,44]$} \\
\hline Diabetes & Mice & $\begin{array}{l}\text { Fed with a high-fat } \\
\text { diet in live as } \\
\text { well as the } \\
\text { pasteurized form }\end{array}$ & $\begin{array}{l}\text { Expression of } \\
\text { Amuc_1100 (an outer } \\
\text { membrane protein); } \\
\text { enhances the glucose } \\
\text { metabolism and } \\
\text { functioning of the gut } \\
\text { barrier }\end{array}$ & Abundance of A. muciniphila & {$[45]$} \\
\hline Diabetes & $\begin{array}{l}\text { Human } \\
\text { patients }\end{array}$ & $\begin{array}{l}\text { Diabetics: } \\
\text { prediabetics, } \\
\text { newly diagnosed } \\
\text { and undergoing } \\
\text { treatment }\end{array}$ & $\begin{array}{l}\text { Negatively correlated } \\
\text { with HbA1c and showed } \\
\text { a positive correlation } \\
\text { with total antioxidants }\end{array}$ & $\begin{array}{l}\text { Abundance of Megasphaera, Escherichia, } \\
\text { Acidaminococcus, Sutterella, and } \\
\text { Akkermansia }\end{array}$ & [19] \\
\hline Diabetes & Human & $\begin{array}{l}\text { Patients with } \\
\text { T2DM and } \\
\text { diabetic } \\
\text { retinopathy }\end{array}$ & $\begin{array}{l}\text { Healthy individuals } \\
\text { benefited }\end{array}$ & $\begin{array}{l}\text { Interactions of two hubs (Akkermansia and } \\
\text { Barnesiella) with four pathogenic hubs } \\
\text { (Gardnerella, Cloacibacillus, Leptotrichia, } \\
\text { and Anaerobiospirillum) }\end{array}$ & [14] \\
\hline Cancer & Human & $\begin{array}{l}\text { Patients with } \\
\text { colorectal } \\
\text { carcinoma }\end{array}$ & $\begin{array}{l}\text { Marked reduction in } \\
\text { butyrate and acetate } \\
\text { concentration }\end{array}$ & $\begin{array}{l}\text { Lower butyrate-producing bacteria and a } \\
\text { 4-fold increase in A. muciniphila }\end{array}$ & [46] \\
\hline Cancer & Human & $\begin{array}{l}\text { Treated with } \\
\text { various immune } \\
\text { checkpoint } \\
\text { inhibitors (ICIs) }\end{array}$ & $\begin{array}{l}\text { Patient undergoing } \\
\text { antibiotics treatment has } \\
\text { a poorer response to ICI } \\
\text { PD-1 antibody. }\end{array}$ & $\begin{array}{l}\text { An increased abundance of Akkermansia in } \\
\text { the intestine of those who responded } \\
\text { positively to the ICI. }\end{array}$ & {$[47]$} \\
\hline
\end{tabular}


Table 1 continued

\begin{tabular}{|c|c|c|c|c|c|}
\hline $\begin{array}{l}\text { Metabolic } \\
\text { disorder }\end{array}$ & Host & Treatment & Metabolic changes & Impact in gut microbiota & References \\
\hline Cancer & Mice & $\begin{array}{l}\text { Employing } \\
\text { extracellular } \\
\text { vesicles derived } \\
\text { from } A \text {. } \\
\text { muciniphila into } \\
\text { immune- } \\
\text { competent mice }\end{array}$ & $\begin{array}{l}\text { Suppressed the } \\
\text { proliferation and } \\
\text { invasion of prostate } \\
\text { cells No toxicity to } \\
\text { normal tissues }\end{array}$ & - & [48] \\
\hline Cancer & Mice & $\begin{array}{l}\text { Oral administration } \\
\text { of live or } \\
\text { pasteurized } \\
\text { Akkermansia }\end{array}$ & $\begin{array}{l}\text { Significantly affected the } \\
\text { metabolome in the liver } \\
\text { and gut: elevating the } \\
\text { intestinal concentrations } \\
\text { of spermidine, } \\
\text { polyamines, Short-chain } \\
\text { fatty acids, and } \\
\text { 2-hydroxybutyrate }\end{array}$ & $\begin{array}{l}\text { Pasteurized Akkermansia were more effective } \\
\text { than live Akkermansia }\end{array}$ & [49] \\
\hline Longevity & Human & $\begin{array}{l}\text { Gut microbiota } \\
\text { analysis }\end{array}$ & $\begin{array}{l}\text { Showed association with } \\
\text { longevity }\end{array}$ & $\begin{array}{l}\text { highest diversity of Ruminococcaceae; } \\
\text { lower prevalence of Prevotellaceae members } \\
\text { (in centenarians): Alistipes, Akkermansia, } \\
\text { and Ruminococcoaceae }\end{array}$ & [18] \\
\hline Longevity & Mice & $\begin{array}{l}\text { FMT and } \\
\text { transplantation } \\
\text { with } A \text {. } \\
\text { muciniphila into } \\
\text { short-lived } \\
\text { mouse }\end{array}$ & Extended life span & $\begin{array}{l}\text { enhancement in Verrucomicrobia and a } \\
\text { decline in the Proteobacterial species }\end{array}$ & {$[50]$} \\
\hline Atherosclerosis & Human & $\begin{array}{l}\text { Diet free of fat, } \\
\text { sugars and } \\
\text { cholesterol, and } \\
\text { alkaloid, } \\
\text { berberine, } \\
\text { (grapes, barberry, } \\
\text { and turmeric) }\end{array}$ & $\begin{array}{l}\text { Reduced the high-fat diet- } \\
\text { induced atherosclerosis } \\
\text { in } \mathrm{ApoE}^{-/-}\end{array}$ & Abundance of Akkermansia spp. in the gut & {$[51]$} \\
\hline Celiac disease & Human & $\begin{array}{l}\text { Characterization of } \\
\text { amplicon } \\
\text { sequence variants } \\
\text { (ASVs) }\end{array}$ & $\begin{array}{l}\text { A dramatic reduction in } \\
\text { the quantity of ASVs }\end{array}$ & $\begin{array}{l}\text { Dorea and Akkermansia in the fecal } \\
\text { microbiomes }\end{array}$ & {$[17]$} \\
\hline
\end{tabular}

\section{Diabetes}

Gut microbiota participate actively in intestinal physiology. The altered composition of GM, inflammation and disruption of the gut barrier are significant symptoms of type 2 diabetes (T2D) and obesity. In rodents and humans, A. mucinophila, a mucin degrader harboring in the mucus layer, is negatively correlated with body weight. Feeding A. muciniphila reversed metabolic disorders, including insulin resistance and adipose tissue inflammation induced by the high-fat diet. The administration of A. muciniphila enhanced the concentration of anti-inflammatory compounds-endocannabinoids, the gut barrier, and the secretion of peptides. It showed that the cross-talk between the microbiota and the host could assist in overcoming these metabolic disorders [42]. Patients undergoing treatment for Colombian T2DMs using the drug-metformin had a significantly higher population density of $\mathrm{A}$. mисiniphila and SCFA-producers, such as Butyrivibri, Bifidobacteria, and Megasphaera, compared to controls (Table 1) $[43,44]$. The role of this bacterium in improving the metabolic activities of T2DM in mice fed with a highfat diet in live as well as the pasteurized form was reported to be due to the expression of Amuc_1100 (an outer membrane protein). This protein activates insulin and tolllike receptor 2 signaling, which enhances the glucose metabolism and functioning of the gut barrier [45]. A change in the GM of freshly diagnosed T2D patients 
compared to healthy non-diabetic individuals showed an abundance of Firmicutes and Proteobacteria, especially Lactobacillus. It was accompanied by a significant decrease in Bacteroidetes and Verrucomicrobia represented by Prevotella, Akkermansia, Blautia, and Ruminococcus. Patients undergoing diabetic treatment compared to those who had been recently diagnosed were observed to have an abundance of Acidaminococcus, Escherichia, Megasphaera, Sutterella, and Akkermansia. The proportion of Akkermansia showed a negative correlation with $\mathrm{HbA} 1 \mathrm{c}$ and a positive relationship with total antioxidant content [19]. A more complicated scenario was present in the gut of patients with T2DM and diabetic retinopathy (DR) and compared with healthy subjects. The microbiome of healthy individuals shared Coprobacillus and Gardneralla with T2DM and Cloacibacillus and Synergistes with DR. The five hub genera unique to healthy individuals were: Akkermansia, Leptotrichia Barnesiella, Anaerovibrio, and Anaerobiospirillum). Among the nine networks, healthy individuals benefited from the interactions of two hubs (Akkermansia and Barnesiella) with four pathogenic hubs (Leptotrichia, Cloacibacillus Gardnerella, and Anaerobiospirillum) [14].

\section{Cancer}

Efforts to manage cancer have been constantly made primarily through the use of food components. Studies showing the role of Akkermansia in colorectal carcinoma have been quite limited. The fecal analysis revealed a marked reduction in butyrate and acetate concentration in CRC patients in comparison to normal subjects. The entire bacterial communities were the same in CRC and controls. However, a correlation was established between lower butyrate-producing bacteria and a fourfold increase in $A$. muciniphila (Table 1) [46]. Based on observation on 249 cancer patients which treated with various immune checkpoint inhibitors (ICIs), a linkage was seen between Akkermansia and the drugs. The two major observations were as follows: (1) patient undergoing antibiotics treatment has a poorer response to ICI PD-1 antibody, and (2) an enhanced abundance of Akkermansia in the intestine of those who responded positively to the ICI. The potential application of these findings was supported by the positive response to ICI PD1 in the case of fecal microbial transplantation (FMT) from the patient to a sterile mouse [47]. The efficacy of human prostrate cancer (PCa) drug was improved by employing extracellular vesicles derived from A. munciniphila (Akk-EVs). Intravenously injected $A k k$ EVs into immune-competent mice led to a significant reduction in the tumor stress of PCa. It did not cause any toxicity to normal tissues. Under in vitro conditions, these vesicles enhanced the number of M1-like macrophages,
$\mathrm{GZMB}^{+} \mathrm{CD}^{+}$cells, and $\mathrm{IFN}-\gamma^{+} \mathrm{CD} 8^{+} \mathrm{T}$ cells. These expressions suppressed the invasion and proliferation of prostate cells [48]. Oral administration of pasteurized or live Akkermansia to mice brought in significant changes in the metabolome of the liver and gut. Here, the pasteurized Akkermanisa were more effective than live Akkermansia in reducing the intestinal concentrations of spermidine, polyamines, SCFAs, and 2-hydroxybutyrate. These metabolites provided information regarding the functioning of Akkermansia [49].

\section{Longevity}

Gut microbiota in centenarians from geographically diverse populations provided clues for identifying signature microbial species. The highest diversity of Ruminococcaceae members were the most prevalent bacteria among these individuals. A distinctly lower prevalence of Prevotellaceae members was present in the GM of Indian centenarians. The signature taxa identified to contribute towards longevity were Akkermansia, Alistipes, and $R u$ minococcoaceae D16. The role of sulphur compounds in longevity was reported in promoting Akkermansia and Alistipes. The lower population density of Prevotella species in centenarians is justified since these bacteria have inherently low SCFA producing capacity and reduced carbohydrate-active enzymes. Chronic inflammation is associated with their abundance. The study did not show any positive correlation in the population densities of Christensenellaceae and Bifidobacterium, and Faecalibacterium. However, their association with longevity had been reported previously (Table 1) [18]. Based on the information that mouse dysbiosis is related to increased abundance of Proteobacteria and cyanobacteria on the one hand and reduced quantity of Verrucomicrobia, GM of human progeria patients was also analyzed. These patients displayed similar variations in their GM. Centenarians exhibited a significant enhancement in Verrucomicrobia and a decline in the Proteobacterial species. FMT and transplantation with A. muciniphila into short-lived mouse strains extended their lifespan, supporting the observation that A. muciniphila has an antiaging impact [50].

\section{Other Disorders}

Another disorder where arteries get blocked due to high cholesterol levels is atherosclerosis. A diet free of sugars, cholesterol, and fat has been recommended for managing this metabolic disorder. Plants containing high concentrations of an alkaloid, berberine, such as grapes, barberry, and turmeric, have been used for medicinal purposes. Berberine mixed with drinking water resulted in enhancing the population of Akkermansia spp. in the gut and reduced 
the high-fat diet-induced atherosclerosis in $\mathrm{ApoE}^{-1-}$ (Table 1) [51]. Duodenal microbiomes of celiac disease $(\mathrm{CeD})$ and their first-degree relatives (FDRs) were characterized by the significant presence of amplicon sequence variants (ASVs) of different genera. In contrast, $\mathrm{CeD}$ had a significantly higher abundance of ASVs belonging to Helicobacter and Megasphaera species. In contrast, FDRs were distinguished by an abundance of ASVs representing Actinomyces, Anaerostipes, Bifidobacterium, Gemella, Granulicatella, and Parvimonas genera. A dramatic reduction in the quantity of ASVs from Dorea and Akkermansia in the fecal microbiomes of FDRs and $\mathrm{CeD}$ was observed compared to the microbiota of the control group [17].

\section{Childbirth and Growth}

Another relatively new insight has been provided by microbiome analysis of babies delivered through vaginal and cesarean procedures. The baby delivery process influences the gut microbial diversity in children. The dominant bacterial populations in Indian and Finnish children were Bacteroides, and Streptococcus species in vaginally born subjects. In contrast, children delivered through the cesarean system had a predominance of Escherichia, and Akkermansia. Vaginally delivered children had a high abundance of Clostridium, Collinsella, Megamonas, Megasphaera, Rummeliibacillus, and Veillonella, while higher Lactobacillus was present in the children born through the cesarean operation. Microbial community analysis to predict the predominant metabolic activities revealed that Indian children's microbial genes were involved in glycan biosynthesis and metabolisms of glycan and proteins for the biosynthesis of lipopolysaccharide. Finnish children's gut microbiota possessed genes responsible for carbohydrate and methane metabolisms. The study also showed that mucin degrading Akkermansia spp. was in significantly higher abundance in Finnish children. It showed a negative correlation with a high-fat diet [52]. Children having stunted growth expressed a decrease in Actinobacteria and a marked increase in the abundance of Bacteroidetes with age. Akkermansia (2.65\%) were among the ten most abundant genera, whose contribution to the manifestation of the abnormality was observed to fluctuate as follows: significant decrease at 3 and 18 months, a substantial increase in the cases at 6, 8, and 21-month stage compared to their respective controls [53].

\section{Improving Health via FMT}

A strategy to regain and maintain health has been developed by manipulating GM through FMT from healthy individuals. FMT from humans to mice has shown significant improvements in reversing diseased (dysbiosis) conditions to normal (eubiosis). Various potential benefits of FMT strategy in restoring health have been reported: (a) enhances insulin sensitivity in patients with metabolic syndrome [54]; (b) obesity and general metabolism in mice and humans [55, 56]; (c) diabetes [57]; (d) treating individuals for refractory ICI-associated colitis [58]; (e) preventing recurrent Clostridium difficile infections [59-61]; (f) restoring metabolic homeostasis [62]; (g) lifespan [50]. Rodents receiving FMT from cancer patients acquired their inabilities to respond to immunotherapeutic treatments using ICIs [47, 63].

Interestingly, in contrast to FMT, application of a single bacterium (A. muciniphila) has also proved beneficial in treating various disorders: (a) the lifespan in progeria, (b) the health of mammals and aged mice [29, 42, 45, 64]; (c) activation of bile acid metabolism in mice $[65,66]$. A clinical trial has validated the anti-obesity and antidiabetic effects of Akkermansia [45, 67].

By regulating the food items, we consume and their quantities, it is possible to manipulate the population densities of the different bacteria (Fig. 2). The consumption of fibers can proportionately increase the diversity of these probiotic bacterial species in the gut. Bacteria metabolize these fibers, and the fermentation results in the production of SCFAs, which nourish the gut barrier, enhance immunity and reduce inflammation [68]. Vegetables, herbal tea, fruits, red wine, and dark chocolate can come in handy in regaining the lost bacterial diversity. The essential components in these food items are the polyphenols - which have unique properties - the most important being their antioxidant characteristic [69]. Prebiotics, probiotics, and phytobiotics have chemical components such as dietary fibers (Fruits, vegetables, nuts, legumes, whole grains), which are beneficial for maintaining a healthy microbiota within the gut [32, 70-72]. Together these reduce the risk of metabolic, endocrine, and immune functions and cancer [73-75]. It was suggested that a healthy diet might be instrumental in better prognosis of infected with COVID-19 patients during the lockdown [76, 77] . We must remember that maintaining a healthy microbiome is imperative to ensure health [78]. 


\section{Knowledge Gaps and Perspectives}

Efforts to establish an unambiguous correlation between the microbial diversity and population dynamic of GM, and the health status of human beings and animals, are being made globally. Similar studies have elucidated the role of microbes in the rhizosphere and phyllosphere and the plant growth and yield. The need is to study if these probiotics can prove effective individually or as consortia. Secondly, it is also necessary to identify prebiotics, which will help the probiotics increase and maintain the desired cell density. Further, information is lacking on the potential side effects of the transfer of these bacterial species to unhealthy individuals on a large scale and at high frequency. A clear idea is yet to be made available about the additional features introduced into these probiotic bacteria through genetic engineering to enhance their sustainability and robustness, especially for industrial production. These studies will enable human beings to gain health and remain healthy without synthetic chemical drugs.

\section{Conclusions}

The microbe Akkermansia is proving instrumental in regaining eubiosis and consequently conferring various health benefits. A two-prong strategy is necessary to achieve and maintain good health. A diet rich in prebiotics and FMT from healthy individuals can help us achieve an abundance of probiotic bacteria. A low-fat, high-fiber diet is perhaps an ultimate option to ensure a healthy life.

Acknowledgements This research was supported by the Basic Science Research Program through the National Research Foundation of Korea (NRF) funded by the Ministry of Science, ICT \& Future Planning (NRF-2021R1I1A1A01060963, NRF2020R1I1A1A01073483). This paper was supported by Konkuk University Researcher Fund in 2020.

\section{References}

1. Gupta V, Sood U, Kumar R, Lal R, Kalia VC (2020) Microbiome: a new lease to microbiology. Indian J Microbiol 60:1. https://doi.org/10.1007/s12088-019-00852-8

2. Sender R, Fuchs S, Milo R (2016) Revised estimates for the number of human and bacteria cells in the body. PLoS Biol 14:e1002533. https://doi.org/10.1371/journal.pbio.1002533

3. Gilbert JA, Blaser MJ, Caporaso JG et al (2018) Current understanding of the human microbiome. Nat Med 24:392-400. https:// doi.org/10.1038/nm.4517

4. Rowland I, Gibson G, Heinken A et al (2018) Gut microbiota functions: metabolism of nutrients and other food components. Eur J Nutr 57:1-24. https://doi.org/10.1007/s00394-017-1445-8

5. Blaser MJ (2014) The microbiome revolution. J Clin Invest 124:4162-4165. https://doi.org/10.1172/jci78366
6. Kulkarni AS, Kumbhare SV, Dhotre DP, Shouche YS (2019) Mining the core gut microbiome from a sample Indian population. Indian J Microbiol 59:90-95. https://doi.org/10.1007/ s12088-018-0742-0

7. Kumar R, Sood U, Gupta V, Singh M, Scaria J, Lal R (2020) Recent advancements in the development of modern probiotics for restoring human gut microbiome dysbiosis. Indian J Microbiol 60:12-25. https://doi.org/10.1007/s12088-019-00808-y

8. Sood U, Gupta V, Kumar R et al (2020) Chicken gut microbiome and human health: Past scenarios, current perspectives, and futuristic applications. Indian J Microbiol 60:2-11. https://doi. org/10.1007/s12088-019-00785-2

9. Diaz Carrasco JM, Casanova NA, Fernández Miyakawa ME (2019) Microbiota, gut health and chicken productivity: what is the connection? Microorganisms 7:374. https://doi.org/10.3390/ microorganisms 7100374

10. Milanović V, Cardinali F, Aquilanti L et al (2020) A glimpse into the microbiota of marketed ready-to-eat crickets (Acheta domesticus). Indian J Microbiol 60:115-118. https://doi.org/10. 1007/s12088-019-00817-x

11. Kalia VC (2019) Pharmaceutical and personal care product contamination: a global scenario. In: Prasad MNV, Kapley A, Vithanage MM (eds) Pharmaceuticals and personal care products: waste management and treatment technology-emerging contaminants and micro pollutants. Elsevier Inc, New York, pp 27-61. https://doi.org/10.1016/B978-0-12-816189-0.00002-0

12. Raffa CM, Chiampo F (2021) Bioremediation of agricultural soil polluted with pesticides: a review. Bioengineering 8:92. https:// doi.org/10.3390/bioengineering 8070092

13. Maji A, Misra R, Dhakan DB et al (2018) Gut microbiome contributes to impairment of immunity in pulmonary tuberculosis patients by alteration of butyrate and propionate producers. Environ Microbiol 20:402-419. https://doi.org/10.1111/14622920.14015

14. Das T, Jayasudha R, Chakravarthy $\mathrm{S}$ et al (2021) Alterations in the gut bacterial microbiome in people with type 2 diabetes mellitus and diabetic retinopathy. Sci Rep 11:2738. https://doi. org/10.1038/s41598-021-82538-0

15. Iebba V, Totino V, Gagliardi A et al (2016) Eubiosis and dysbiosis: the two sides of the microbiota. New Microbiol 39:1-12

16. Sood U, Bajaj A, Kumar R, Khurana S, Kalia VC (2018) Infection and microbiome: impact of tuberculosis on human gut microbiome of Indian cohort. Indian J Microbiol 58:123-125. https://doi.org/10.1007/s12088-018-0706-4

17. Bodkhe R, Shetty SA, Dhotre DP et al (2019) Comparison of small gut and whole gut microbiota of first-degree relatives with adult celiac disease patients and controls. Front Microbiol 10:164. https://doi.org/10.3389/fmicb.2019.00164

18. Tuikhar N, Keisam S, Labala RK et al (2019) Comparative analysis of the gut microbiota in centenarians and young adults shows a common signature across genotypically non-related populations. Mech Ageing Dev 179:23-35. https://doi.org/10. 1016/j.mad.2019.02.001

19. Gaike AH, Paul D, Bhute S et al (2020) The gut microbial diversity of newly diagnosed diabetics but not of prediabetics is significantly different from that of healthy nondiabetics. mSystems 5:e00578-e00519. https://doi.org/10.1128/mSystems. 00578-19

20. Coetzer WG, Coetzee LM et al (2021) A preliminary assessment of skin microbiome diversity of Zebrafish (Danio rerio): South African pet shop fish. Indian J Microbiol 61:81-84. https://doi. org/10.1007/s12088-020-00900-8

21. Cornick S, Tawiah A, Chadee K (2015) Roles and regulation of the mucus barrier in the gut. Tissue Barriers 3:e982426. https:// doi.org/10.4161/21688370.2014.982426 
22. Ng KM, Ferreyra JA, Higginbottom SK et al (2013) Microbiotaliberated host sugars facilitate post-antibiotic expansion of enteric pathogens. Nature 502:96-99. https://doi.org/10.1038/ nature 12503

23. Petersson J, Schreiber O, Hansson GC et al (2011) Importance and regulation of the colonic mucus barrier in a mouse model of colitis. Am J Physiol Gastrointest Liver Physiol 300:G327-G333. https://doi.org/10.1152/ajpgi.00422.2010

24. Cani PD, de Vos WM (2017) Next-generation beneficial microbes: the case of Akkermansia muciniphila. Front Microbiol 8:1765. https://doi.org/10.3389/fmicb.2017.01765

25. Naito Y, Uchiyama K, Tkakgi T (2018) A next-generation beneficial microbe: Akkermansia muciniphila. J Clin Biochem Nutr 63:33-35. https://doi.org/10.3164/jcbn.18-57

26. Derrien M, Vaughan EE, Plugge CM, de Vos WM (2004) Akkermansia municiphila gen. nov., sp. nov., a human intestinal mucin-degrading bacterium. Int $J$ Syst Evol Microbiol 54:1469-1476. https://doi.org/10.1099/ijs.0.02873-0

27. Belzer C, de Vos WM (2012) Microbes inside-from diversity to function: the case of Akkermansia. ISME J 6:1449-1458. https:// doi.org/10.1038/ismej.2012.6

28. O'Keefe SJ, Li JV, Lahti L et al (2015) Fat, fibre and cancer risk in African Americans and rural Africans. Nat Commun 6:6342. https://doi.org/10.1038/ncomms 7342

29. Schneeberger M, Everard A, Gómez-Valadés AG et al (2015) Akkermansia muciniphila inversely correlates with the onset of inflammation, altered adipose tissue metabolism and metabolic disorders during obesity in mice. Sci Rep 5:16643. https://doi. org/10.1038/srep16643

30. Han M, Wang C, Liu P, Li D, Li Y, Ma X (2017) Dietary fiber gap and host gut microbiota. Protein Peptide Lett 24:388-396. doi: https://doi.org/10.2174/0929866524666170220113312

31. Borda-Molina D, Seifert J, Camarinha-Silva A (2018) Current perspectives of the chicken gastrointestinal tract and its microbiome. Comput Struct Biotechnol J 16:131-139. https://doi.org/ 10.1016/J.CSBJ.2018.03.002

32. Clavijo V, Flórez MJV (2018) The gastrointestinal microbiome and its association with the control of pathogens in broiler chicken production: A review. Poult Sci 97:1006-1021. https:// doi.org/10.3382/ps/pex359

33. Baldwin J, Collins B, Wolf PG et al (2016) Table grape consumption reduces adiposity and markers of hepatic lipogenesis and alters gut microbiota in butter fat-fed mice. J Nutr Biochem 27:123-135. https://doi.org/10.1016/j.jnutbio.2015.08.027

34. Shen W, Shen M, Zhao X et al (2017) Anti-obesity effect of capsaicin in mice fed with high-fat diet is associated with an increase in population of the gut bacterium Akkermansia muciniphila. Front Pharmacol 8:272. https://doi.org/10.3389/fmicb. 2017.00272

35. Zhao S, Liu W, Wang J et al (2017) Akkermansia muciniphila improves metabolic profiles by reducing inflammation in chow diet-fed mice. J Mol Endocrinol 58:1-14. https://doi.org/10.1530/ JME-16-0054

36. Anhe FF, Roy D, Pilon G et al (2015) A polyphenol-rich cranberry extract protects from diet-induced obesity, insulin resistance and intestinal inflammation in association with increased Akkermansia spp. population in the gut microbiota of mice. Gut 64:872-883. https://doi.org/10.1136/gutjnl-2014-307142

37. Roopchand DE, Carmody RN, Kuhn P et al (2015) Dietary polyphenols promote growth of the gut bacterium Akkermansia muciniphila and attenuate high-fat diet-induced metabolic syndrome. Diabetes 64:2847-2858. doi: https://doi.org/10.2337/ db14-1916

38. Masumoto S, Terao A, Yamamoto Y et al (2016) Non-absorbable apple procyanidins prevent obesity associated with gut microbial and metabolomic changes. Sci Rep 6:31208. https://doi.org/10. 1038/srep31208

39. Nakanishi M, Chen Y, Qendro V et al (2016) Effects of walnut consumption on colon carcinogenesis and microbial community structure. Cancer Prevent Res 9:692-703. https://doi.org/10.1158/ 1940-6207CAPR-16-0026

40. Kawabata K, Yoshioka Y, Terao J (2019) Role of intestinal microbiota in the bioavailability and physiological functions of dietary polyphenols. Molecules 24:370. https://doi.org/10.3390/ molecules 24020370

41. Tu P, Bian X, Chi L et al (2018) Characterization of the functional changes in mouse gut microbiome associated with increased Akkermansia muciniphila population modulated by dietary black raspberries. ACS Omega 3:10927-10937. https:// doi.org/10.1021/acsomega.8b00064

42. Everard A, Belzer C, Geurts L et al (2013) Cross-talk between Akkermansia muciniphila and intestinal epithelium controls dietinduced obesity. Proc Natl Acad Sci USA 110:9066-9071. https://doi.org/10.1073/pnas.1219451110

43. de la Cuesta-Zuluaga J, Mueller NT, Corrales-Agudelo V et al (2017) Metformin is associated with higher relative abundance of mucin-degrading Akkermansia muciniphila and several shortchain fatty acid-producing microbiota in the gut. Diabetes Care 40:54-62. https://doi.org/10.2337/dc16-1324

44. Wu H, Esteve E, Tremaroli V et al (2017) Metformin alters the gut microbiome of individuals with treatment-naive type 2 diabetes, contributing to the therapeutic effects of the drug. Nat Med 23:850-858. https://doi.org/10.1038/nm.4345

45. Plovier H, Everard A, Druart C et al (2017) A purified membrane protein from Akkermansia muciniphila or the pasteurized bacterium improves metabolism in obese and diabetic mice. Nat Med 23:107-113. doi: https://doi.org/10.1038/nm.4236

46. Weir TL, Manter DK, Sheflin AM et al (2013) Stool microbiome and metabolome differences between colorectal cancer patients and healthy adults. PLoS ONE 8:e70803. doi: https://doi.org/10. 1371/journal.pone.0070803

47. Routy B, Le Chatelier E, Derosa L et al (2018) Gut microbiome influences efficacy of PD-1-based immunotherapy against epithelial tumors. Science 359:91-97. https://doi.org/10.1126/sci ence.aan3706

48. Luo ZW, Xia K, Liu YW et al (2021) Extracellular vesicles from Akkermansia muciniphila elicit antitumor immunity against prostate cancer via modulation of $\mathrm{CD}^{+} \mathrm{T}$ cells and macrophages. Int J Nanomed 16:2949-2963. https://doi.org/10.2147/ IJN.S304515

49. Grajeda-Iglesias C, Durand S, Daillère R et al (2021) Oral administration of Akkermansia muciniphila elevates systemic antiaging and anticancer metabolites. Aging 13:6375-6405. https://doi.org/10.18632/aging.202739

50. Bárcena C, Valdés-Mas R, Mayoral P et al (2019) Healthspan and lifespan extension by fecal microbiota transplantation into progeroid mice. Nat Med 25:1234-1242. https://doi.org/10.1038/ s41591-019-0504-5

51. Zhu L, Zhang D, Zhu $\mathrm{H}$ et al (2018) Berberine treatment increases Akkermansia in the gut and improves high-fat dietinduced atherosclerosis in Apoe-/- mice. Atherosclerosis 268:117-126. https://doi.org/10.1016/j.atherosclerosis.2017.11. 023

52. Kumbhare SV, Kumar H, Chowdhury SP et al (2017) A crosssectional comparative study of gut bacterial community of Indian and Finnish children. Sci Rep 7:10555. https://doi.org/10.1038/ s41598-017-11215-y

53. Dinh DM, Ramadass B, Kattula D et al (2016) Longitudinal analysis of the intestinal microbiota in persistently stunted young children in South India. PLoS ONE 11:e0155405. https://doi.org/ 10.1371/journal.pone.0155405 
54. Vrieze A, Van Nood E, Holleman F et al (2012) Transfer of intestinal microbiota from lean donors increases insulin sensitivity in individuals with metabolic syndrome. Gastroenterology 143:913-916. https://doi.org/10.1053/j.gastro.2012.06.031

55. Ridaura VK, Faith JJ, Rey FE et al (2013) Gut microbiota from twins discordant for obesity modulate metabolism in mice. Science 341:1241214. https://doi.org/10.1126/science.1241214

56. Cox LM, Yamanishi S, Sohn J et al (2014) Altering the intestinal microbiota during a critical developmental window has lasting metabolic consequences. Cell 158:705-721. https://doi.org/10. 1016/j.cell.2014.05.052

57. Leshem A, Horesh N, Elinav E (2019) Fecal microbial transplantation and its potential application in cardiometabolic syndrome. Front Immunol 10:1341. https://doi.org/10.3389/fimmu. 2019.01341

58. Wang Y, Wiesnoski DH, Helmink BA et al (2018) Fecal microbiota transplantation for refractory immune checkpoint inhibitor-associated colitis. Nat Med 24:1804-1808. https://doi. org/10.1038/s41591-018-0238-9

59. van Nood E, Vrieze A, Nieuwdorp M et al (2013) Duodenal infusion of donor feces for recurrent Clostridium difficile. N Engl J Med 368:407-415. https://doi.org/10.1056/NEJMoa1205037

60. Weingarden AR, Chen C, Bobr A et al (2014) Microbiota transplantation restores normal fecal bile acid composition in recurrent Clostridium difficile infection. Am J Physiol Gastrointest Liver Physiol 306:G310-G319. https://doi.org/10.1152/ajpgi. 00282.2013

61. Buffie CG, Bucci V, Stein RR et al (2015) Precision microbiome reconstitution restores bile acid mediated resistance to Clostridium difficile. Nature 517:205-208. https://doi.org/10.1038/ nature 13828

62. Zarrinpar A, Chaix A, Xu ZZ et al (2018) Antibiotic-induced microbiome depletion alters metabolic homeostasis by affecting gut signaling and colonic metabolism. Nat Commun 9:2872. https://doi.org/10.1038/s41467-018-05336-9

63. Fluckiger A, Daillère R, Sassi M et al (2020) Cross-reactivity between tumor MHC class I-restricted antigens and an enterococcal bacteriophage. Science 369:936-942. https://doi.org/10. 1126/science.aax0701

64. Bodogai M, O’Connell J, Kim K et al (2018) Commensal bacteria contribute to insulin resistance in aging by activating innate B1a cells. Sci Transl Med 10:eaat4271. https://doi.org/10.1126/sci translmed.aat4271

65. de Aguiar Vallim TQ, Tarling EJ, Edwards PA (2013) Pleiotropic roles of bile acids in metabolism. Cell Metab 17:657-669. https:// doi.org/10.1016/j.cmet.2013.03.013

66. Pierre JF, Martinez KB, Ye H et al (2016) Activation of bile acid signaling improves metabolic phenotypes in high-fat diet-induced obese mice. Am J Physiol Gastrointest Liver Physiol 311:G286G304. https://doi.org/10.1152/ajpgi.00202.2016
67. Depommier C, Everard A, Druart C et al (2019) Supplementation with Akkermansia muciniphila in overweight and obese human volunteers: a proof-of-concept exploratory study. Nat Med 25:1096-1103. https://doi.org/10.1038/s41591-019-0495-2

68. De Vadder F, Kovatcheva-Datchary P, Goncalves D et al (2014) Microbiota-generated metabolites promote metabolic benefits via gut-brain neural circuits. Cell 156:84-96. https://doi.org/10.1016/ j.cell.2013.12.016

69. Jayachandran M, Chung SSM, Xu B (2019) A critical review of the relationship between dietary components, the gut microbe Akkermansia muciniphila, and human health. Crit Rev Food Sci 60:2265-2276. https://doi.org/10.1080/10408398.2019.1632789

70. Azad MAK, Sarker M, Li T, Yin J (2018) Probiotic species in the modulation of gut microbiota: an overview. Biomed Res Int 2018:9478630. https://doi.org/10.1155/2018/9478630

71. Bajagai YS, Alsemgeest J, Moore RJ, Van TTH, Stanley D (2020) Phytogenic products, used as alternatives to antibiotic growth promoters, modify the intestinal microbiota derived from a range of production systems: an in vitro model. Appl Microbiol Biotechnol 104:10631-10640. https://doi.org/10.1007/s00253020-10998-x

72. Lee J-K, Patel SKS, Sung BH, Kalia VC (2020) Biomolecules from municipal and food industry wastes: an overview. Bioresour Technol 298:122346. https://doi.org/10.1016/j.biortech.2019. 122346

73. Coutzac C, Jouniaux JM, Paci A et al (2020) Systemic short chain fatty acids limit antitumor effect of CTLA-4 blockade in hosts with cancer. Nat Commun 11:2168. https://doi.org/10.1038/ s41467-020-16079-x

74. Silva YP, Bernardi A, Frozza RL (2020) The role of short-chain fatty acids from gut microbiota in gut-brain communication. Front Endocrinol 11:25. https://doi.org/10.3389/fendo.2020. 00025

75. Kalia VC, Patel SKS, Cho B-K, Wood TK, Lee J-K (2021) Emerging applications of bacteria as anti-tumor agents. Sem Cancer Biol. https://doi.org/10.1016/j.semcancer.2021.05.012

76. Patel SKS, Lee JK, Kalia VC (2020) Deploying biomolecules as antii-COVID-19 agents. Indian J Microbiol 60:263-268. https:// doi.org/10.1007/s12088-020-00893-4

77. Rishi P, Thakur K, Vij S et al (2020) Diet, gut microbiota and COVID-19. Indian J Microbiol 60:420-429. https://doi.org/10. 1007/s12088-020-00908-0

78. Singhvi N, Gupta V, Gaur M et al (2020) Interplay of human gut microbiome in health and wellness. Indian J Microbiol 60:26-36. https://doi.org/10.1007/s12088-019-00825-x

Publisher's Note Springer Nature remains neutral with regard to jurisdictional claims in published maps and institutional affiliations. 